\title{
REDUÇÃO DA QUANTIDADE DE VINHAÇA ATRAVÉS DA EVAPORAÇÃO
}

\section{Túlio Camaçarí de Carvalho ${ }^{1}$}

\section{Celso Luiz da Silva ${ }^{2}$}

Resumo: A perspectiva de aumento da produção de álcool combustível causa preocupação a respeito da vinhaça, subproduto da destilação do etanol de cana. A vinhaça é um poluente com alto teor de orgânicos e que precisa ser tratada. Atualmente, a utilização da vinhaça in natura no solo é comum, porém, há controvérsias sobre salinização do solo e contaminação de aqüíferos subterrâneos. Dentre os processos de tratamento da vinhaça, encontram-se na literatura científica, vários trabalhos a respeito da fertirrigação e digestão anaeróbia, mas não a respeito da evaporação da vinhaça, que pode ser realizada através de evaporadores tipo falling film. $\mathrm{O}$ objetivo deste trabalho é avaliar o potencial de redução da quantidade de vinhaça através da evaporação, o que não descarta a utilização da vinhaça concentrada como fertilizante. Para isto, elaborou-se o balanço de massa e energia de uma planta de evaporação de vinhaça localizada na cidade de Potirendaba - SP, confrontando os resultados obtidos com os dados obtidos na unidade. A unidade de evaporação tem capacidade de processar cerca de $100 \mathrm{~m}^{3} / \mathrm{h}$ de vinhaça, retornando cerca de $80 \mathrm{~m}^{3} / \mathrm{h}$ de água para o processo da usina. $\mathrm{O}$ balanço foi elaborado através de um software comercial $\left(\right.$ Sugars $^{\mathrm{TM}}{ }^{\mathrm{M}}$ ). Os resultados obtidos pela simulação refletiram os dados coletados na planta.

Palavras-chave: Evaporação. Vinhaça. Falling Film.

\footnotetext{
${ }^{1}$ Graduado em Engenharia Química, Faculdade de Engenharia de Bauru - UNESP, Depto. de Engenharia Mecânica. tulio_carvalho@hotmail.com.

${ }^{2}$ Doutor em Engenharia Mecânica/Térmica, Faculdade de Engenharia de Bauru - UNESP, Depto. de Engenharia Mecânica.celsos@feb.unesp.br.
} 


\section{INTRODUÇÃO}

Nos últimos anos, as oscilações do preço do barril do petróleo, as projeções de escassez para as fontes petrolíferas e os problemas ambientais oriundos da queima desses combustíveis têm feito o mundo refletir sobre alternativas que possam ser inseridas na matriz energética global. A tendência é a busca por combustíveis renováveis e menos agressivos ao meio ambiente como o etanol brasileiro.

Ao final do processo de fabricação do etanol, ocorre a produção de vinhaça. Trata-se de um líquido de coloração marrom escura, proveniente da destilação do caldo fermentado de cana-de-açúcar, que apresenta elevada demanda bioquímica de oxigênio e é produzida na proporção média de 13 litros por litro de álcool destilado. (NETO, 2008).

A perspectiva de aumento da produção de etanol combustível é fato marcante devido ao aumento da frota veicular (criação dos veículos flex fuel) e ao consumo de álcool anidro no mercado interno e externo, o que faz crescer a preocupação com o destino a ser dado à vinhaça (SIQUEIRA, 2008).

A vinhaça é um poluente com alto teor de orgânicos e que precisa ser tratada. Sua disposição em qualquer coleção hídrica foi proibida pela portaria $n^{\circ} 323$ de 29 de novembro de 1978 do extinto Ministério do Interior. Atualmente, a utilização da vinhaça através da fertirrigação é comum e impede que seja descartada nos corpos aquáticos, possibilitando a fertilização dos solos agricultáveis, além da redução dos custos de plantio. Porém, há controvérsias sobre salinização excessiva do solo e contaminação de aqüíferos subterrâneos (SALOMON, 2007).

A fertirrigação promove a dispersão "in natura" de um volume de vinhaça que varia entre 400 a $500 \mathrm{~m}^{3} / \mathrm{ha}$, aumentando as quantidades de cálcio, potássio, nitrogênio e fósforo no solo. Considerando a dispersão em áreas próximas às unidades produtoras, durante anos consecutivos, devido à redução de custos de transportes e disponibilidade de recursos e equipamentos adequados, o volume de vinhaça aplicado supera o recomendado. (GRANATO, 2003).

Corazza (2001) identificou quatro grupos de opções tecnológicas para destinação da vinhaça: evaporação, fermentação aeróbia, digestão anaeróbia e outros usos (fertirrigação e reciclagem na fermentação alcoólica). 
Encontram-se na literatura científica, vários trabalhos a respeito da fertirrigação e digestão anaeróbia, mas não a respeito da evaporação da vinhaça. Atualmente, no Brasil duas usinas já possuem plantas de evaporação de vinhaça em operação.

O objetivo deste trabalho é avaliar o potencial de redução da quantidade de vinhaça e conseqüentemente a redução na captação de água por parte das usinas através da evaporação, o que não descarta a utilização da vinhaça concentrada como fertilizante visando à redução de custos na compra de fertilizantes industrializados.

\section{REVISÃO BIBLIOGRÁFICA}

\subsection{VINHAÇA}

Vinhaça: líquido derivado da destilação do vinho, que é resultante da fermentação do caldo da cana ou do melaço, subproduto do processo de fabricação de açúcar (COMPANHIA DE TECNOLOGIA DE SANEAMENTO AMBIENTAL - CETESB, 2005). Trata-se de um produto constituído por sais e de elevada DBO e DQO.

Nas décadas de 40 e 50, a quantidade de vinhaça produzida não era tão grande como nos dias atuais, sendo depositada nos mananciais e em áreas de sacrifício, mas mesmo assim, já despertava preocupação nos órgãos ambientais e na comunidade científica (CORAZZA, 2001).

Em 1975, o governo criou o Proálcool, visando incentivar a produção de álcool para compor uma mistura com a gasolina e assim diminuir a dependência do país em relação ao petróleo. Em meados da década de 70, o país produzia cerca de 580 milhões de litros e em 1980 a produção chegou a 3.676 milhões. (PAIXÃO, 2006). Esse aumento da produção de etanol representava um aumento proporcional na produção de vinhaça. Em 1978, a portaria $n^{\circ} 323$ do Ministério do Interior proibiu a disposição da vinhaça nos mananciais.

Constatado o valor da vinhaça como fertilizante devido principalmente aos teores de potássio, cálcio e magnésio e pelo alto teor de matéria orgânica, a disposição da mesma diretamente no solo passou a ser a solução mais empregada pelas usinas, muito embora, isso representasse um risco para contaminação do lençol freático (VIANA, 2006). 
A produção atual de etanol chegou a 22 bilhões de litros por ano (UNIÃO DA INDÚSTRIA DE CANA DE AÇÚCAR - UNICA, 2009), representando também um aumento gigantesco na produção de vinhaça.

Em março de 2005, a Companhia de Tecnologia de Saneamento Ambiental (CETESB) homologou a norma técnica P4. 231 - Vinhaça - Critérios e Procedimentos para Aplicação no Solo Agrícola. Essa norma baseia-se nas legislações federal e estadual e nas normas da ABNT e determina dentre os critérios e procedimentos que a concentração máxima de potássio no solo não poderá exceder $5 \%$ da Capacidade de Troca lônica CTC. Caso esse limite seja atingido, a aplicação da vinhaça fica restrita em função da extração média pela cana de açúcar, que é de 185 kg de $\mathrm{K}_{2} \mathrm{O}$ por hectare por corte.

\subsection{EVAPORAÇÃO DA VINHAÇA}

Os primeiros registros sobre evaporadores de vinhaça datam de 1954, quando a empresa austríaca Vogelbusch instalou um sistema concentrador que se utilizava de evaporadores inclinados tipo termo-sifão. Pouco tempo depois, a mesma empresa desenvolveu o evaporador falling film, ou película fina que se utiliza do princípio de evaporação de filme descendente. (BIASE, 2007)

No Brasil, as duas primeiras instalações para se concentrar a vinhaça foram instaladas em 1978. Uma delas foi instalada na Usina Tiúma em Pernambuco e foi projetada por uma empresa nacional chamada Borag, sendo integrada à destilaria de álcool da usina. A instalação teve muitos problemas de incrustações e as paradas para limpeza dificultavam a operação da destilaria. Atualmente, tanto o sistema de concentração quanto à usina estão desativados. (BIASE, 2007)

A outra unidade foi instalada na Usina Santa Elisa em São Paulo e foi fabricada pela empresa brasileira Conger sob licença da Vogelbusch. A unidade ficou parada em função do alto consumo de energia, mas em 1999 com a implantação do sistema de co-geração de energia elétrica na usina, a unidade passou a funcionar continuamente, produzindo cerca de $3 \mathrm{~m}^{3} / \mathrm{h}$ de vinhaça concentrada. $\mathrm{O}$ sistema permitiu que a usina reduzisse 0 custo de transporte da vinhaça para as regiões mais afastadas e pudesse ter a flexibilidade de dosar a concentração de cada aplicação de vinhaça conforme as 
características do solo. Para a aplicação da vinhaça concentrada ao solo, foi desenvolvido um caminhão tanque com bomba de pressurização e barra aplicadora de sete metros de largura que possibilitou a dosagem em cerca de 5.000 ha. (BARBOSA, 2006; BIASE, 2007).

Em 1984, a Destilaria Santa Izabel, em Novo Horizonte, São Paulo, instalou um conjunto de evaporação de vinhaça que permitia uma redução de até cinqüenta por cento do volume total de vinhaça produzido, que era distribuído por caminhões como fertiirrigação na lavoura. Atualmente, a empresa brasileira Dedini é detentora da licença da Vogelbusch para fabricação dos evaporadores de vinhaça e em consórcio com as empresas Siemens e Chemtech comercializou uma planta completa de destilação de álcool integrada com evaporadores de vinhaça para a empresa petrolífera da Venezuela PDVSA. A unidade tem capacidade de produção de 8,5 milhões de litros de álcool por ano (BIASE, 2007).

\subsection{O PROCESSO DA EVAPORAÇÃO}

A evaporação é uma operação unitária que é largamente utilizada nos diversos ramos da indústria química e de processos que tem o objetivo de obter produtos mais concentrados, ou seja, com menor porcentual de um soluto volátil, na maioria das vezes a água. Os evaporadores são utilizados na indústria alimentícia, de papel e celulose, sucroalcooleira, de polímeros, de fertilizantes, de compostos orgânicos e inorgânicos, dentre outras.

A energia para evaporação, na maioria das vezes, é obtida do vapor saturado proveniente das caldeiras, o qual não entra em contato direto com o produto que se deseja evaporar. Nas usinas sucroalcooleiras, a evaporação para produção de açúcar utiliza vapor proveniente das turbinas de geração elétrica, sendo saturado e com pressão de $1,5 \mathrm{kgf} / \mathrm{cm}^{2}$ manométrica. Utiliza-se o termo vapor vivo para designar o vapor de aquecimento de um evaporador e vapor vegetal para designar o vapor de água proveniente da evaporação. A Figura (1) apresenta um esquema típico de um evaporador.

Todo evaporador consiste em uma superfície de aquecimento onde ocorre a transferência de calor do fluido de aquecimento para o fluido de processo e de um meio 
onde ocorre a separação do vapor evaporado do fluido concentrado. O que difere os diferentes tipos de evaporadores é como a separação entre o vapor vegetal e o fluido concentrado é feita (FRANCO, 2001).

Referências acadêmicas (WESTPHALEN 1999; FRANCO, 2001) descrevem os principais tipos de evaporadores e os arranjos utilizados, dentre os quais, pode-se citar: evaporadores solares, tachos em batelada, evaporadores com circulação natural, evaporadores com circulação forçada, evaporadores de filme descendente, evaporadores de filme agitado e evaporadores de placas.

Os evaporadores são grandes consumidores de energia, em vista disso, são utilizadas várias estratégias para se diminuir o consumo de energia, como o sistema de evaporação em múltiplos efeitos. Neste arranjo, um evaporador é montado seqüencialmente ao outro, de modo que o vapor vegetal de um evaporador (primeiro efeito) é utilizado para aquecer outro evaporador (segundo efeito) e assim sucessivamente. O vapor evaporado no último efeito passa por um condensador, encerrando o processo.

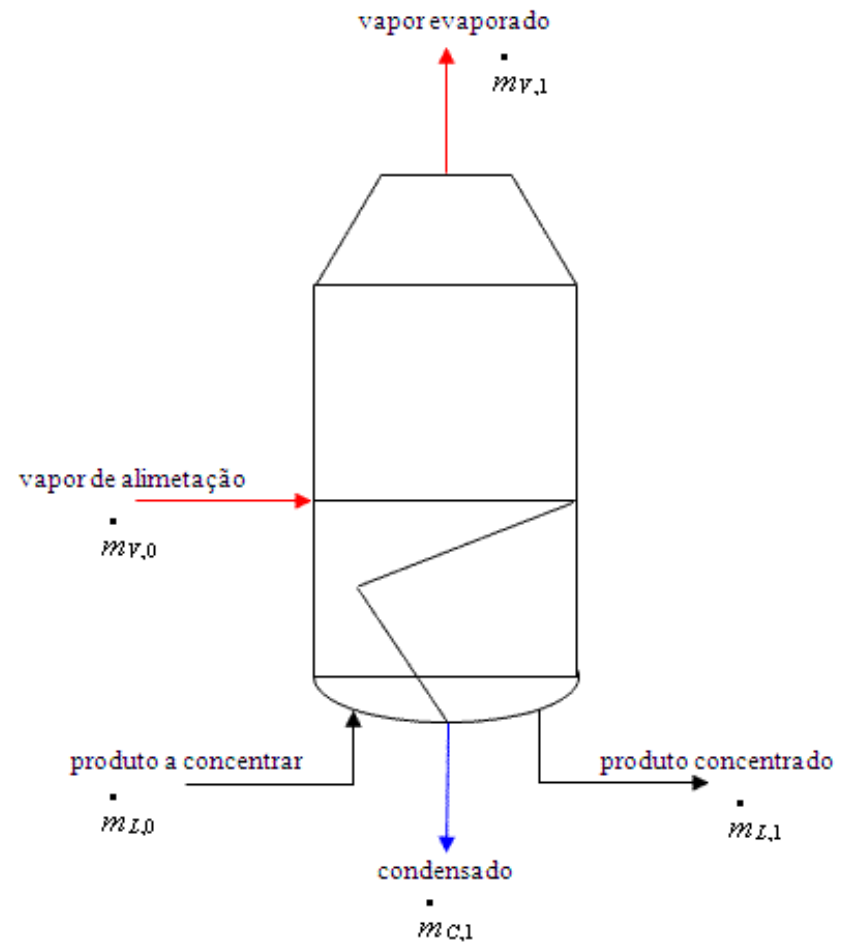

Figura 1. Esquema típico de um evaporador. 


\section{MATERIAL E MÉTODOS}

Para que se pudessem alcançar os objetivos almejados no presente trabalho, utilizouse de informações técnicas e dados coletados em uma planta produtora de álcool e açúcar (Usina Cerradinho - Potirendaba-SP), onde encontra-se em operação um sistema de evaporação, fabricado pela empresa brasileira Citrotec, destinado a concentrar a vinhaça. A usina produz $500 \mathrm{~m}^{3} /$ dia de álcool e $250 \mathrm{~m}^{3} / \mathrm{h}$ de vinhaça.

A unidade de evaporação desta usina é constituída por cinco efeitos, opera com vapor vegetal extraído do sistema de evaporação de caldo da usina e tem capacidade para concentrar cerca de $100 \mathrm{~m}^{3} / \mathrm{h}$ de vinhaça, o restante da vinhaça produzida é aplicado "in natura" como fertiirrigação. Separadores de arraste estão instalados entre um efeito e outro para evitar o arraste de gotículas de vinhaça para o próximo efeito.

Nesta usina, a vinhaça "in natura" (produzida na destilação do álcool) tem concentração de 3 a 5 Brix ( $3 \%$ a $5 \%$ em concentração mássica de sólidos) e $3,37 \mathrm{~kg} / \mathrm{m}^{3}$ de $\mathrm{K}_{2} \mathrm{O}$. Após passar pelo processo de concentração, 18 a $20 \mathrm{~m}^{3} / \mathrm{h}$ de vinhaça com concentração de 20 a 25 Brix e $30 \mathrm{~kg} / \mathrm{m}^{3}$ de $\mathrm{K}_{2} \mathrm{O}$ são produzidas.

Os dados obtidos nas coletas realizadas nesta planta foram processados por um software comercial específico denominado Sugars ${ }^{\mathrm{TM}}$, que permite o cálculo dos fluxos de massa e energia no processo para posterior análise. O modelo utilizado está na seqüência de equações apresentadas a seguir.

\subsection{BALANÇO DE MASSA E ENERGIA EM SISTEMAS DE EVAPORAÇÃO}

Considerando um único efeito conforme mostrado na Fig. (1), podem-se definir as seguintes equações para o balanço de massa do equipamento.

$$
\dot{m}_{V, 0}+\dot{m}_{L, 0}=\dot{m}_{V, 1}+\dot{m}_{L, 1}+\dot{m}_{C, 1}
$$




$$
\dot{m_{V, 0}}=\dot{m}_{C, 1}
$$

$\therefore \dot{m}_{L, 1}=\dot{m}_{L, 0}-\dot{m}_{V, 1}$

Para os sólidos dissolvidos presentes no líquido, pode-se definir a equação:

$$
\dot{m}_{L, 0} \cdot w_{D S, 0}=\dot{m}_{L, 1} \cdot w_{D S, 1}
$$

Sendo que $w_{D S, 0}$ é a concentração mássica de sólidos no líquido a concentrar e $w_{D S, 1}$ é a concentração mássica de sólidos no líquido concentrado.

$O$ balanço de energia pode ser definido pela seguinte equação:

$$
\dot{m}_{V, 0} \cdot h_{V, 0}+\dot{m}_{L, 0} \cdot h_{L, 0}=\dot{m}_{V, 1} \cdot h_{V, 1}+\dot{m}_{L, 1} \cdot h_{L, 1}+\dot{m}_{C, 1} \cdot h_{C, 1}+\dot{Q}_{\text {perdido }}
$$

Onde $h$ representa a entalpia de cada um dos fluxos e $\dot{Q}_{\text {perdido }}$ é a taxa de calor perdida no processo de evaporação.

Usando a Equação (2) pode-se definir:

$$
\dot{m}_{V, 0} \cdot\left(h_{V, 0}-h_{C, 1}\right)+\dot{m}_{L, 0} \cdot h_{L, 0}=\dot{m}_{V, 1} \cdot h_{V, 1}+\dot{m}_{L, 1} \cdot h_{L, 1}+\dot{Q}_{\text {perdido }}
$$

Usando a Equação (3) e assumindo que o condensado não é sub-resfriado, têm-se:

$$
\begin{aligned}
& \dot{m}_{V, 0} \cdot \Delta h_{V L}+\dot{m}_{L, 0} \cdot h_{L, 0}=\dot{m}_{V, 1} \cdot h_{V, 1}+\dot{m}_{L, 0} \cdot h_{L, 1}-\dot{m}_{V, 1} \cdot h_{L, 1}+\dot{Q}_{\text {perdido }} \\
& \therefore \dot{m}_{V, 1}=\frac{\left(\dot{m}_{V, 0} \cdot \Delta h_{V L}+\dot{m}_{L, 0} \cdot\left(h_{L, 0}-h_{L, 1}\right)-\dot{Q}_{\text {perdido }}\right)}{\left(h_{V, 1}-h_{L, 1}\right)}
\end{aligned}
$$


$\Delta h_{V L}$ é o calor específico de evaporação.

A Equação (8) pode ser simplificada com algumas considerações. Se não há perdas de calor, $Q_{\text {perdido }}=0$.

Se também considerar-se que todas as entalpias dos líquidos são iguais e que o calor específico da evaporação não muda com a pressão e temperatura, a Eq. (8) pode ser reduzida em:

$$
\dot{m}_{V, i}=\dot{m}_{V, i-1}
$$

A Equação (9) indica que $1 \mathrm{~kg}$ de vapor evapora $1 \mathrm{~kg}$ de água. Esta simplificação é útil e ajuda no entendimento da evaporação com múltiplos efeitos, podendo oferecer bons resultados, particularmente a altas pressões (REIN, 2007).

$\mathrm{O}$ balanço de massa e energia para um sistema de evaporação com $\mathrm{N}$ efeitos é feito considerando-se cada um dos vasos de evaporação (balanços individuais) e todo o conjunto (balanço global), considerando estado estacionário. Inicialmente, considera-se desprezível o flash do condensado formado entre os efeitos. As equações a seguir descrevem o balanço de massa e energia global do sistema. O vapor extraído do efeito i é

representado por $\dot{m}_{V B, i}$. O vapor proveniente do efeito i para o próximo efeito é representado por $\dot{m}_{V, i}$.

$$
\begin{aligned}
& \dot{m}_{V, 0}+\dot{m}_{L, 0}=\dot{m}_{V, N}+\dot{m}_{L, N}+\sum_{i=1}^{N} \dot{m}_{C, i}+\sum_{i=1}^{N} \dot{m}_{V B, i} \\
& \dot{m}_{L, 0} \cdot w_{D S, 0}=\dot{m}_{L, N} \cdot w_{D S, N} \\
& \dot{m}_{V, 0} \cdot h_{V, 0}+\dot{m}_{L, 0} \cdot h_{L, 0}=\dot{m}_{V, N} \cdot h_{V, N}+\dot{m}_{L, N} \cdot h_{L, N}+\sum_{i=1}^{N} \dot{m}_{C, i} \cdot h_{C, i}+\sum_{i=1}^{N} \dot{Q}_{\text {perdidai }}+\sum_{i=1}^{N} \dot{m}_{V B, i} \cdot h_{V, i}
\end{aligned}
$$


Para o efeito i do sistema de evaporação a múltiplos efeitos, pode-se definir:

$$
\begin{aligned}
& \dot{m}_{V, i-1}+\dot{m}_{L, i-1}=\dot{m}_{V, i}+\dot{m}_{V B, i}+\dot{m}_{L, i}+\dot{m}_{C, i} \\
& \dot{m}_{V, i-1}=\dot{m}_{C, i} \\
& \therefore \dot{m}_{L, i}=\dot{m}_{L, i-1}-\dot{m}_{V, i}-\dot{m}_{V B, i} \\
& \dot{m}_{L, i-1} \cdot w_{D S, i-1}=\dot{m}_{L, i} \cdot w_{D S, i} \\
& \dot{m}_{V, i-1} \cdot h_{V, i-1}+\dot{m}_{L, i-1} \cdot h_{L, i-1}=\dot{m}_{V, i} \cdot h_{V, i}+\dot{m}_{V B, i} \cdot h_{V, i}+\dot{m}_{L, i} \cdot h_{L, i}+\dot{m}_{C, i} \cdot h_{C, i}+\dot{Q}_{p e r d i d Q i}
\end{aligned}
$$

Utilizando a Equação (14):

$\dot{m}_{V, i-1} \cdot\left(h_{V, i-1}-h_{C, i}\right)+\dot{m}_{L, i-1} \cdot h_{L, i-1}=\dot{m}_{V, i} \cdot h_{V, i}+\dot{m}_{V B, i} \cdot h_{V, i}+\dot{m}_{L, i} \cdot h_{L, i}+\dot{Q}_{p e r d i d a, ~}$

Para o cálculo do vapor que flui de um efeito para o outro, utiliza-se da Eq. (15) na Eq. (18):

$$
\begin{aligned}
& \dot{m}_{V, i-1} \cdot \Delta h_{V L, i-1}+\dot{m}_{L, i-1} \cdot h_{L, i-1}=\dot{m}_{V, i} \cdot h_{V, i}+\left(\dot{m}_{L, i-1}-\dot{m}_{V, i}-\dot{m}_{V B, i}\right) \cdot h_{L, i}+\dot{Q}_{p e r d i d a i} \\
& \therefore \dot{m}_{V, i}=\frac{\left(\dot{m}_{V, i-1} \cdot \Delta h_{V L, i-1}+\dot{m}_{L, i-1} \cdot\left(h_{L, i-1}-h_{L, i}\right)-\dot{m}_{V B, i} \cdot\left(h_{V, i}-h_{L, i}\right)-\dot{Q}_{p e r d i d a i}\right)}{\left(h_{V, i}-h_{L, i}\right)}
\end{aligned}
$$

O vapor total gerado pelo efeito i pode ser calculado pela Eq. (21) a seguir: 


$$
\left(\dot{m}_{V, i}+\dot{m}_{V B, i}\right)=\frac{\left(\dot{m}_{V, i-1} \cdot \Delta h_{V L, i-1}+\dot{m}_{L, i-1} \cdot\left(h_{L, i-1}-h_{L, i}\right)-\dot{Q}_{\text {perdida }, i}\right)}{\left(h_{V, i}-h_{L, i}\right)}
$$

O calor transmitido pelo vapor que condensa pode ser calculado pela equação a seguir:

$$
\dot{Q_{i}}=\dot{m_{V, i-1}} \cdot\left(h_{V, i-1}-h_{C, i}\right)
$$

O calor transmitido também pode ser calculado pela Eq. (23):

$$
\dot{Q}_{i}=k \cdot A \cdot\left(t_{V}-t_{i}\right)
$$

Onde $\mathrm{k}$ é o coeficiente global de transferência de calor, $t_{V}$ a temperatura do vapor que condensa e $t_{i}$ a temperatura do líquido do efeito i. A área $A$ é definida como a área total dos tubos do evaporador.

As equações acima para múltiplos efeitos requerem cálculos por tentativa e erro que podem ser conduzidos por um pacote matemático ou por uma planilha que executa cálculos interativos. A convergência geralmente é rápida (REIN, 2007).

\section{RESULTADOS E DISCUSSÃO}

O balanço de massa e energia da unidade de evaporação de vinhaça foi feito através de um software comercial denominado Sugars ${ }^{\mathrm{TM}}$. O software é utilizado para fazer simulações de processo para as fábricas de açúcar de cana e beterraba, sendo possível calcular os fluxos de matéria, calor e cor das correntes envolvidas no processo. Os resultados são obtidos com um erro de $0,01 \%$. O programa foi desenvolvido para Windows, sendo que a representação gráfica das simulações é feita pelo Visio. 
Os dados reais da planta utilizados para alimentar o software se encontram na Tabela (1). Os efeitos operam sob vácuo progressivo de maneira que as temperaturas decrescem de um efeito para o outro. As informações da Tab. (1) foram inseridas em janelas como as mostradas na Fig. (2) e na Fig. (3). O modelo gráfico ilustrado na Fig. (4) foi criado para que o software fizesse os cálculos. A Tabela (2) apresenta os resultados principais obtidos pela simulação.

A Figura (2) apresenta a janela de propriedades de um fluxo externo criado no Sugars $^{\mathrm{TM}}$. O termo "externo" se refere a toda corrente de entrada no balanço. $\mathrm{O}$ termo "interno" se refere às correntes entre equipamentos, cujas propriedades são calculadas pelo software. Para toda corrente de fluxo externo criada, propriedades como pressão, temperatura, vazão mássica, brix (concentração de sólidos) devem ser informadas para que o software calcule propriedades como vazão volumétrica, densidade, entalpia e calor específico.

Equipamentos como trocadores de calor, evaporadores, decantadores, tanques, misturadores, centrífugas também têm suas respectivas janelas de cálculo. Em tais janelas, propriedades como pressão, temperatura, brix e coeficientes de transferência de calor são solicitadas para permitir que o software calcule o balanço do equipamento. $A$ Figura (3) mostra a janela de propriedades para um evaporador. Neste caso, para que o software faça o balanço, é necessário preencher um dos três conjuntos de propriedades: transferência de calor, vapor de saída ou fluxo de saída de produto.

Tabela 1. Dados obtidos da unidade de evaporação de vinhaça em Potirendaba - SP, Novembro de 2009.

\begin{tabular}{cc}
\hline Variáveis & Valores \\
\hline Vazão de vinhaça na alimentação $\left(\mathrm{m}^{3} / \mathrm{h}\right)$ & 105 \\
Temperatura da vinhaça na alimentação $\left({ }^{\circ} \mathrm{C}\right)$ & 80 \\
Brix da vinhaça na alimentação $(\%)$ & 4,5 \\
Temperatura de saturação do vapor de alimentação $\left({ }^{\circ} \mathrm{C}\right)$ & 115 \\
Temperatura do vapor extraído no $1^{\circ}$ efeito $\left({ }^{\circ} \mathrm{C}\right)$ & 94 \\
Temperatura do vapor extraído no $2^{\circ}$ efeito $\left({ }^{\circ} \mathrm{C}\right)$ & 91
\end{tabular}




\section{Periódica Eletrânica

Temperatura do vapor extraído no $3^{\circ}$ efeito $\left({ }^{\circ} \mathrm{C}\right)$

Temperatura do vapor extraído no $4^{\circ}$ efeito $\left({ }^{\circ} \mathrm{C}\right)$

Temperatura do vapor extraído no $5^{\circ}$ efeito $\left({ }^{\circ} \mathrm{C}\right)$

Fonte: Usina Cerradinho, Potirendaba - SP.

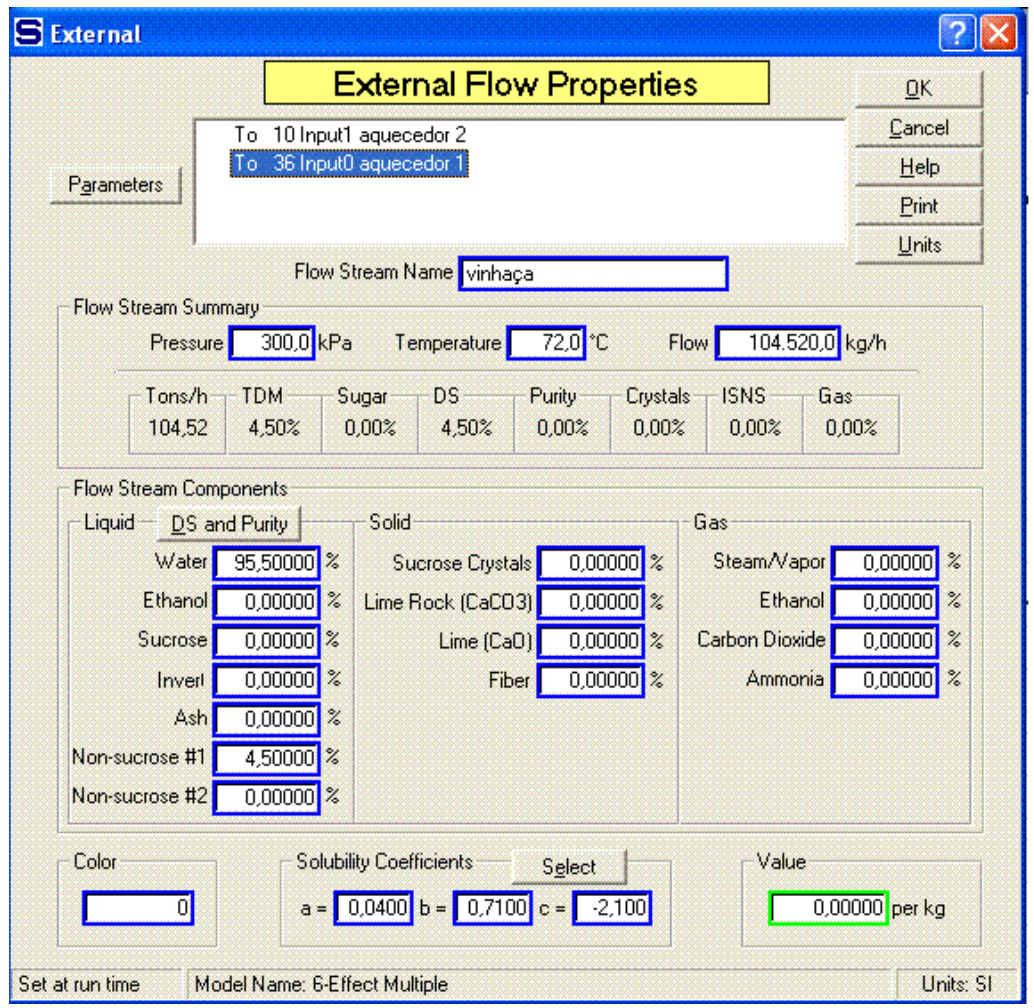

Figura 2. Propriedades de um fluxo externo. 


\section{Periódica Eletrânica

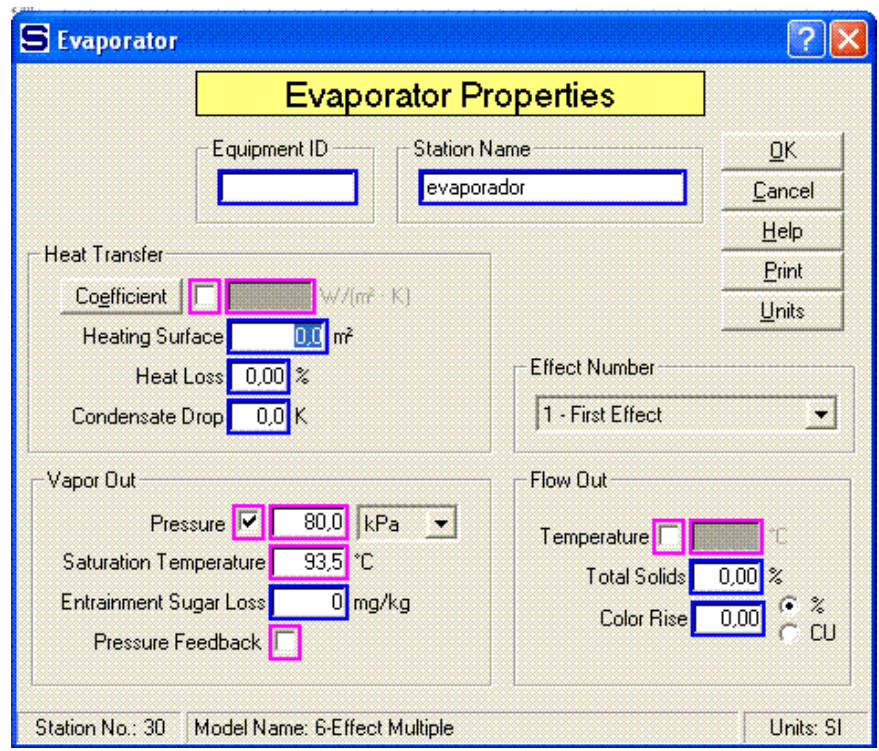

Figura 3. Propriedades de um efeito de evaporação.

Tabela 2. Resultados obtidos pela simulação de processo, Março de 2010.

\begin{tabular}{cc}
\hline Variáveis & Valores \\
\hline Vazão de vinhaça concentrada $\left(\mathrm{m}^{3} / \mathrm{h}\right)$ & 20 \\
Temperatura da vinhaça concentrada $\left({ }^{\circ} \mathrm{C}\right)$ & 62 \\
Brix da vinhaça concentrada $(\%)$ & 21,6 \\
Vazão de condensado final $(\mathrm{t} / \mathrm{h})$ & 82 \\
Brix após $1^{\circ}$ efeito $\left({ }^{\circ} \mathrm{C}\right)$ & 5,4 \\
Brix após $2^{\circ}$ efeito $\left({ }^{\circ} \mathrm{C}\right)$ & 6,6 \\
Brix após $3^{\circ}$ efeito $\left({ }^{\circ} \mathrm{C}\right)$ & 8,4 \\
Brix após $4^{\circ}$ efeito $\left({ }^{\circ} \mathrm{C}\right)$ & 12,0
\end{tabular}

Fonte: Resultados do software Sugars ${ }^{\mathrm{TM}}$. 


\section{Periódica Eletrônica

Conforme informação da usina a unidade de evaporação de vinhaça tem capacidade de produzir 18 a $20 \mathrm{~m}^{3} / \mathrm{h}$ a $60^{\circ} \mathrm{C}$ de vinhaça com concentração de 20 a 25 Brix a partir de cerca de $100 \mathrm{~m}^{3} / \mathrm{h}$ de vinhaça in natura com 3 a 5 de Brix, produzindo cerca de $80 \mathrm{~m}^{3} / \mathrm{h}$ de condensado, que retorna para utilização no processo da usina. Portanto, os resultados obtidos mostrados na Tab. (2) estão de acordo com as informações coletadas na usina.

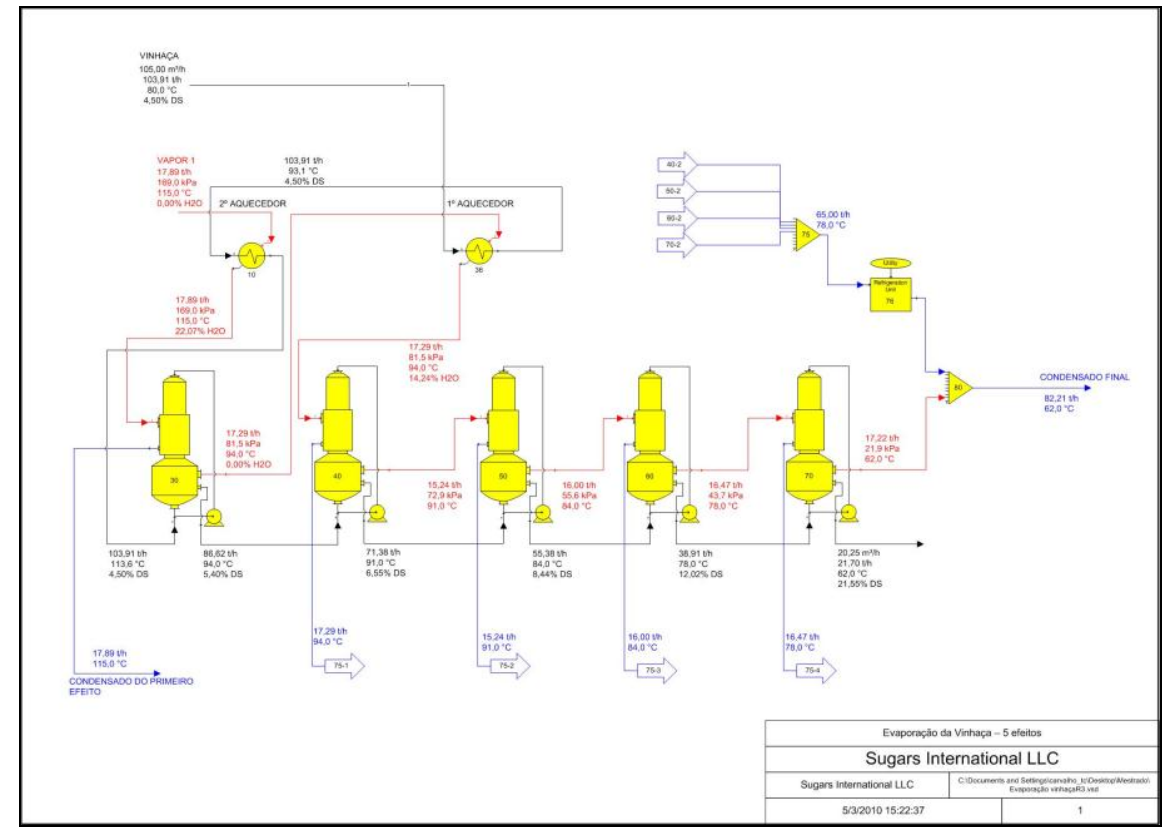

Figura 4. Representação gráfica da simulação no Sugars ${ }^{T M}$.

A Figura (4) mostra a representação gráfica feita no software para se obter o balanço de massa e energia da planta de evaporação de vinhaça. São cinco efeitos de evaporação, precedidos por dois aquecedores (trocadores de calor casco e tubos). $\mathrm{O}$ vapor de alimentação utilizado é saturado e tem pressão de 1,7 bar (170 kPa) e temperatura de $115^{\circ} \mathrm{C}$. Pela simulação, a planta consome cerca $18 \mathrm{t} / \mathrm{h}$ de vapor de alimentação, porém esta informação não pode ser confrontada com a vazão real, pois a usina não disponibilizou esse dado. 


\section{CONCLUSÕES}

Os dados de vazão, brix e temperatura de vinhaça concentrada obtidos pela simulação do Sugars ${ }^{\mathrm{TM}}$ estão bem próximos dos dados reais coletados na unidade, o que demonstra que o modelo pode ser utilizado para simular a planta.

Conclui-se que é possível recuperar cerca de $80 \%$ da água presente na vinhaça com a evaporação da mesma, o que representa economia direta na captação de água para o processo da usina e diminui os custos de transporte da vinhaça para áreas de cana distantes da usina. A evaporação não prejudica as propriedades fertilizantes da vinhaça, já que a mesma, mesmo concentrada é utilizada pela usina como fertilizante das lavouras de cana.

\section{REFERÊNCIAS}

BARBOSA, Valmir et al. Novas tecnologias no uso da vinhaça e aspectos legais. Ed. Tópicos em tecnologia sucroalcoolerira, UNESP. Jaboticabal, 2006, p. 141-150.

BIASE, Luiz Paulo de. Workshop de Gestão de Energia e Resíduos na Agroindústria Sucroalcooleira. Aspectos Gerais da concentração das vinhaças. Pirassununga, 2007. Disponível em: <http://www.fzea.usp.br/green/GERA/Luis\%20Paulo\%20DE\%20Biase.doc>. Acesso em: 20 mai. 2009.

COMPANHIA DE TECNOLOGIA DE SANEAMENTO AMBIENTAL, CETESB. Vinhaça Critérios e procedimentos para aplicação no solo agrícola, Norma Técnica P4. 231. São Paulo, 2005, 12 p.

CORAZZA, Rosana Icassatti. Políticas públicas para tecnologias mais limpas: uma análise das contribuições da economia do meio ambiente. Campinas, 2001. Originalmente apresentada como tese de doutorado, Universidade Estadual de Campinas, 2001.

FRANCO, Max. Integração energética de sistemas de evaporação localizados abaixo do ponto pinch. Campinas, 2001. Originalmente apresentada como dissertação de mestrado, Universidade Estadual de Campinas, 2001. 
GRANATO, Eder Fonzar. Geração de energia através da biodigestão anaeróbica da vinhaça. Bauru, 2003. Originalmente apresentada como dissertação de mestrado, Universidade Estadual Paulista, 2003.

NETO, João Alberto Lelis. Monitoramento de componentes químicos da vinhaça aplicados em diferentes tipos de solo. Piracicaba, 2008. Originalmente apresentada como dissertação de mestrado, Universidade de São Paulo, 2008.

PAIXÂO, Marcelo. O Proálcool Enquanto uma Política Energética Alternativa: uma resenha crítica. Disponível em: <http://www.rits.org.br/pbsd>. Acesso em: 01 nov. 2006.

REIN, Peter. Cane Sugar Engineering. Verlag Dr. Albert Bartens KG. Berlim, Alemanha, 2007, $767 \mathrm{p}$.

SALOMON, Karina. Ribeiro. Avaliação técnico-econômica e ambiental da utilização do biogás proveniente da biodigestão da vinhaça em tecnologias para geração de eletricidade. Itajubá, 2007. Originalmente apresentada como tese de doutorado, Universidade Federal de Itajubá, 2007.

SIQUEIRA, Laura Maria. Influência da taxa de carregamento orgânico na degradação anaeróbia da vinhaça em reator de leito fluidizado. São Carlos, 2008. Originalmente apresentada como dissertação de mestrado, Universidade Federal de São Carlos, 2008.

UNIÃO DA INDÚSTRIA DE CANA-DE-AÇÚCAR - UNICA. Estatísticas. Disponível em: $<$ http://www.unica.com.br/downloads/estatisticas/producaoetanol.xls>. Acesso em 03 mai. 2009.

VIANA, Anderson Bezerra. Tratamento anaeróbio de vinhaça em reator UASB operado em temperatura na faixa termofílica $\left(55^{\circ} \mathrm{C}\right)$ e submetido ao aumento progressivo de carga orgânica. São Carlos, 2006. Originalmente apresentada como dissertação de mestrado, Universidade de São Paulo, 2006.

WESTPHALEN, Denis Libert. Modelagem, simulação e otimização de sistemas de evaporação. Campinas, 1999. Originalmente apresentada como tese de doutorado, Universidade Estadual de Campinas, 1999. 